\title{
Leucemia linfocítica crônica em cão: relato de caso
}

\section{Chronic lymphocitic leukemia in dog: case report}

\author{
Nayro Xavier de Alencar, ${ }^{*}$ André Marcelo Conceição Meneses, ${ }^{* *}$ Aguemi Kohayagawa, ${ }^{* *}$ Regina Kiomi Takahira, ${ }^{* * *}$ \\ Júlio Lopes Sequeira****
}

\begin{abstract}
Resumo
O presente relato refere-se a um caso de leucemia linfocítica crônica (LLC) diagnosticada no Hospital Veterinário da FMVZ UNESP, Campus de Botucatu, em um cão da raça Doberman, fêmea, com nove anos e oito meses de idade que apresentava anorexia e histórico de dificuldade locomotora. Ao exame físico observou-se hepato e esplenomegalia. O diagnóstico foi baseado nos resultados do hemograma (hemácias: 2,4 x 10\%/ $\mu$; hemoglobina: 5,6g/dL; hematócrito: 16\%), linfocitose (40,1 x $\left.10^{3} / \mu \mathrm{L}\right)$ e trombocitopenia $\left(32,5 \times 10^{3} / \mu \mathrm{L}\right)$ e no exame citológico da medula óssea onde se observou celularidade aumentada com hipoplasia severa das séries megacariocítica, mielóide e eritróide. A série linfóide apresentou-se marcadamente aumentada, sendo representada principalmente por linfócitos pequenos e médios e em menor grau por plasmócitos.
\end{abstract}

Palavras-chave: leucemia, doenças linfoproliferativas, medula óssea, cão.

\begin{abstract}
Chronic lymphocytic leukemia (CLL) was diagnosed in a 9-year-old-female Doberman Pinscher presented to the hospital of FMVZ - UNESP, Botucatu with anorexia and locomotion abnormalities. Clinical examination revealed hepato and splenomegaly. The diagnose was based on CBC results which showed anemia (RBC $2.4 \times 10^{6} / \mu \mathrm{L}$; hemoglobin $5.6 \mathrm{~g} / \mathrm{dL}$; PCV $16 \%$ ), lymphocytosis $\left(40.1 \times 10^{3} / \mu \mathrm{L}\right)$ and thrombocytopenia $\left(32.5 \times 10^{3} / \mu \mathrm{L}\right)$ and in bone marrow evaluation which showed increased cellularity with severe myeloid, erythroid and megakaryocytic hypoplasia. The lymphoid series was marked increased, represented mainly by small and medium lymphocytes and occasional plasma cells.
\end{abstract}

Keywords: leukemia, lymphoproliferative disorders, bone marrow, dog.

\section{Introdução}

A leucemia linfocítica crônica (LLC) é uma doença de proliferação descontrolada de uma célula-tronco ou "stem cell" linfóide, malignamente transformada, em que sua progênie tem uma forte tendência para se diferenciar dentro da medula óssea e migrar amplamente através dos tecidos. A circulação destas células é prolongada e resulta em linfocitose periférica, variando de 10.000 a acima de 100.000 células $/ \mathrm{mL}$ de sangue (Helfand e Modiano, 2000).

A leucemia linfocítica crônica (LLC) é rara, sendo descrita mais freqüentemente em animais velhos. Caracteriza-se por uma linfocitose severa envolvendo linfócitos pequenos e médios de aparência normal. O exame da medula óssea também revela um número aumentado de linfócitos de aparência normal (Meyer e Harvey, 1998). O prognóstico a curto prazo é geralmente bom. Muitos animais com LLC sobrevivem por anos somente com tratamento sintomático ou quimioterapia leve (Leifer e Matus, 1985; Helfand e Modiano, 2000).

Em cães e gatos, duas formas principais de leucemias linfóides são reconhecidas: a leucemia linfoblástica aguda (LLA) e leucemia linfocítica crônica (LLC). A LLA geralmente acomete adultos jovens e animais de meia-idade, ao passo que a LLC é mais comum em cães acima de sete anos de idade e gatos de várias idades (Blue et al., 1999, Walker, 1999).

A leucemia linfocítica difere do linfoma maligno (linfossarcoma) primariamente pela distribuição anatômica. A leucemia linfocítica é difusa com envolvimento do sangue, medula óssea, ou ambos, por outro lado, o linfoma maligno tende a ser mais localizado ao tecido e pode ou não progredir para o envolvimento do sangue. Leucemia linfocítica e linfoma maligno geralmente ocorrem simultaneamente e devem ser considerados variantes do mesmo processo patológico e não como doenças diferentes. O estágio leucêmico existe quando números detectáveis de células malignas estão presentes no sangue periférico e medula óssea. Leucemia linfocítica sem crescimento de tumor sólido é um achado pouco comum em cães, de qualquer modo, leucemias concomitantes são geralmente encontradas em pacientes com linfoma maligno disseminado (Thrall, 1981).

O principal achado hematológico na maioria dos casos de LLC é a leucocitose causada pela linfocitose madura. A contagem de linfócitos maduros é geralmente elevada (10.000 a $>100.000 / \mu \mathrm{L})$. Uma leve anemia normocítica normocrômica é um achado comum, e a contagem de plaquetas está normal ou moderadamente reduzida. Citologia do aspirado da

\footnotetext{
* Professor adjunto III da Faculdade de Veterinária - UFF - Niterói/RJ.

** Professor adjunto da Universidade Federal Rural da Amazônia - UFRA - Belém/PA.

*** Professor titular do Departamento de Clínica Veterinária - FMVZ - UNESP Botucatu/SP.

**** Professor assistente doutor do Departamento de Clínica Veterinária - FMVZ - UNESP Botucatu/SP.
} 
medula óssea demonstra aumento significativo do número de linfócitos pequenos compreendendo $>30 \%$ das células nucleadas da medula óssea (Helfand e Modiano, 2000).

\section{Descrição do caso}

Foi atendido no Hospital Veterinário da UNESP, Campus de Botucatu, um cão fêmea, da raça Doberman, com nove anos e oito meses de idade que apresentava anorexia e histórico de dificuldade locomotora. Ao exame físico observou-se apenas hepato e esplenomegalia, sem alteração de linfonodos periféricos.

Solicitou-se, para melhor avaliação do caso, hemograma (Tabela e Figura 1) e exames bioquímicos (Tabela 2). O hemograma revelou anemia, linfocitose e trombocitopenia. Anormalidades bioquímicas incluíam elevação da uréia, da bilirrubina total e direta, e das enzimas alanina amaninotransferase (ALT), gama-glutamiltransferase (GGT) e fosfatase alcalina (FA). Proteína total e albumina sérica estavam levemente diminuídas.

Tabela 1: Resultados obtidos para o hemograma

\begin{tabular}{lcc}
\hline & Animal & $\begin{array}{c}\text { Valor de referência } \\
\text { (Jain, 1993) }\end{array}$ \\
\hline Hemácias $\left(\times 10^{6} / \mu \mathrm{L}\right)$ & 2,4 & $5,5-8,5$ \\
Hemoglobina $(\mathrm{g} / \mathrm{dL})$ & 5,6 & $12,0-18,0$ \\
Hematócrito $(\%)$ & 16 & $37-55$ \\
VCM $(\mathrm{fL})$ & 67 & $60-77$ \\
HCM $(\mathrm{pg})$ & 23 & $19-23$ \\
$\mathrm{CHCM}(\%)$ & 35 & $32-36$ \\
Proteína total $(\mathrm{g} / \mathrm{dL})$ & 6,0 & $6,0-8,0$ \\
Leucócitos $\left(\times 10^{3} / \mu \mathrm{L}\right)$ & 41,8 & $6,0-17,0$ \\
Bastonete $\left(\times 10^{3} / \mu \mathrm{L}\right)$ & 0,42 & $0-0,3$ \\
Neutrófilo $\left(\times 10^{3} / \mu \mathrm{L}\right)$ & 0,84 & $3,0-11,5$ \\
Linfócito $\left(\times 10^{3} / \mu \mathrm{L}\right)$ & 40,1 & $1,0-4,8$ \\
Monócito $\left(\times 10^{3} / \mu \mathrm{L}\right)$ & 0,42 & $0,15-1,35$ \\
Fibrinogênio $(\mathrm{mg} / \mathrm{dL})$ & 500 & $100-500$ \\
Plaquetas $\left(\times 10^{3} / \mu \mathrm{L}\right)$ & 32,5 & $200-500$ \\
\hline
\end{tabular}

Obs: Linfócitos com atipia nuclear, nucléolos evidentes, vacuolizações citoplasmáticas. Presença de manchas de Gümprecht e hemácias em alvo

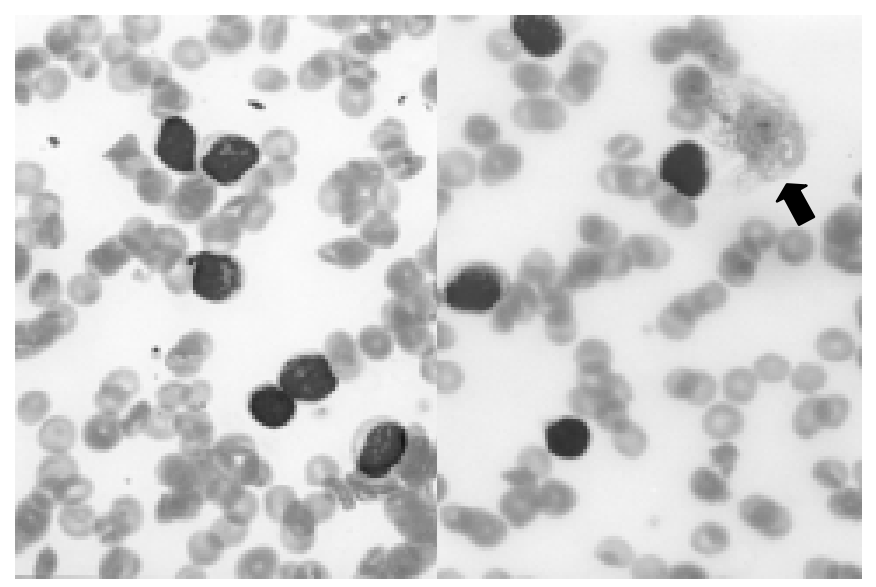

Figura 1: Linfócitos morfologicamente normais no sangue periférico e mancha de Gümprecht (seta) (1000x)
Tabela 2: Valores obtidos para os exames bioquímicos

\begin{tabular}{lcc}
\hline & Animal & $\begin{array}{c}\text { Valor de referência } \\
\text { (Kaneko et al., 1997) }\end{array}$ \\
\hline Uréia $(\mathrm{mg} / \mathrm{dL})$ & 80,5 & $21,4-59,9$ \\
Creatinina $(\mathrm{mg} / \mathrm{dL})$ & 0,5 & $0,5-1,5$ \\
ALT (UI/L) & 133,9 & $21-102$ \\
GGT (UI/L) & 24,9 & $1,2-6,4$ \\
Fosfatase Alcalina (Ul/L) & $4.258,0$ & $20-156$ \\
Bilirrubina total $(\mathrm{g} / \mathrm{dL})$ & 0,5 & $0,1-0,3$ \\
Bilirrubina direta $(\mathrm{g} / \mathrm{dL})$ & 0,4 & $0,06-0,12$ \\
Proteína Total $(\mathrm{g} / \mathrm{dL})$ & 5,3 & $5,4-7,1$ \\
Albumina $(\mathrm{g} / \mathrm{dL})$ & 2,1 & $2,6-3,3$ \\
Globulina $(\mathrm{g} / \mathrm{dL})$ & 3,2 & $2,7-4,4$ \\
\hline
\end{tabular}

Um exame de medula óssea foi solicitado para avaliar melhor os achados do hemograma. O aspirado da medula óssea revelou celularidade aumentada (Figura 2) com hipoplasia severa das séries megacariocítica, mielóide e eritróide. A série linfóide apresentou um aumento marcante (Figura 3), sendo representada principalmente por linfócitos pequenos e médios e em menor grau por plasmócitos. A coloração das

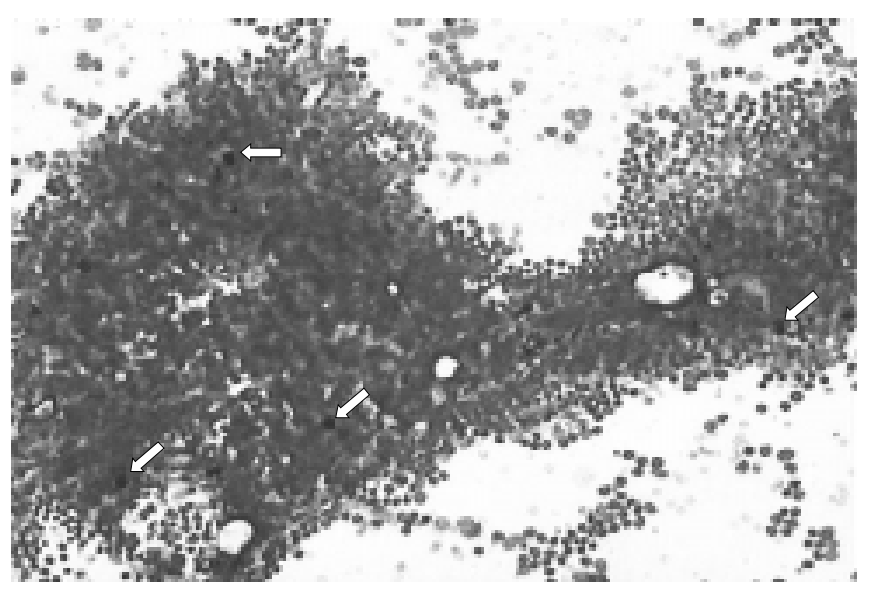

Figura 2: Espícula hiperplásica de medula óssea contendo inúmeras estruturas amorfas compatíveis com hemossiderina (setas) (100x)

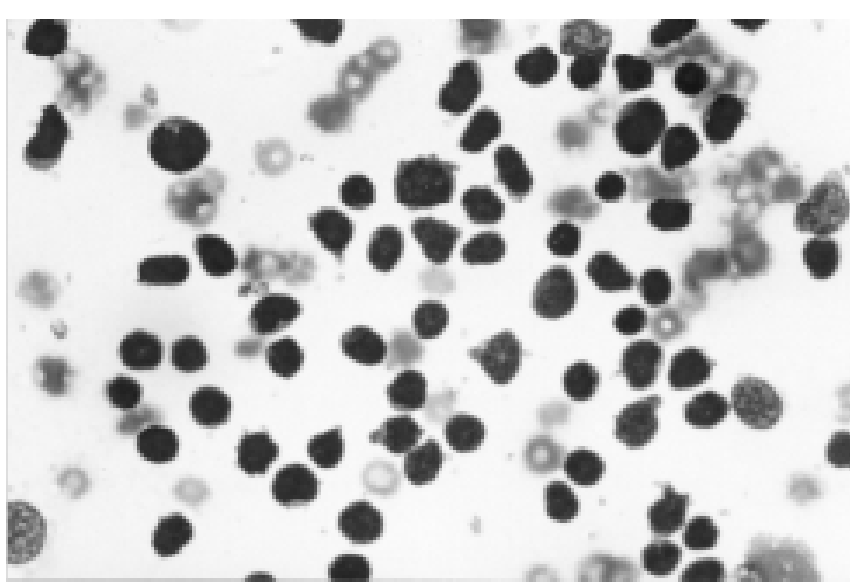

Figura 3: Medula óssea com hiperplasia da série linfóide; linfócitos pequenos e médios (1000x) 
lâminas de medula óssea pelo azul-da-prússia revelou aumento na deposição de ferro medular (hemossiderina).

Os achados hematológicos e citológicos (hemograma e mielograma) confirmaram o diagnóstico de leucemia linfocítica crônica (LLC) para o presente caso. Após o diagnóstico, os proprietários optaram pela eutanásia do animal.

O animal foi submetido à necropsia observando-se a presença de massa neoplásica na região torácica antero-ventral diagnosticado como linfoma tímico. Foi observada ainda infiltração neoplásica nos linfonodos submandibulares, préescapulares, subescapulares, mediastinais e ilíacos, e no fígado.

\section{Discussão}

Vários autores (Leifer e Matus, 1985, Jacobs et al., 2002, MacEwen e Young, 1996, Meyer e Harvey, 1998) descrevem a maior incidência desse tumor em cães de meia-idade e cães velhos (5 - 11 anos), assim como verificado no presente caso (9 anos).

Achados clínicos comuns incluem letargia, anorexia, vômitos esporádicos, espleno ou hepatoesplenomegalia, pirexia, poliúria e polidipsia, hemorragia, claudicação intermitente e colapso. Linfoadenopatia periférica não é observada, em geral (Leifer e Matus, 1985; Helfand e Modiano, 2000, Vail, 2000, Jacobs et al., 2002).

A extensa mieloftise presente foi possivelmente responsável pela anemia, neutropenia e trombocitopenia severas observadas no presente caso, em conformidade com o observado por alguns autores (Thrall, 1981; Vail, 2000, Jacobs et al., 2002). Segundo esses autores, a anemia torna-se aparente quando aproximadamente metade da medula óssea é substituída pelo tecido linfóide.

\section{Referências}

BLUE, J.T.; FRENCH, T. W.; MEYER, D. J. The liver. In: COWELL, R.L.; TYLER, R.D.; MEINKOTH, J.H. (Ed.). Diagnostic Cytology and Hematology of the Dog and Cat. St. Louis: MOSBY, Inc., 1999, p.183194.

HELFAND, S.C.; MODIANO, J.F. Chronic lymphocytic leukemia, In: FELDMAN, B. F.; ZINKL, J. G.; JAIN, N. C. Shalm's Veterinary Hematology. Philadelphia: Lippincott Williams \& Wilkins. 2000, p.638641.

JACOBS, R.M., MESSICK, J.B., VALLI, V.E. Tumors of the Hemolymphatic System. In: MEUTEN, D.J. Tumors in Domestic Animals. Ames: lowa State Press, 2002. p. 119-198.

JAIN, N.C. Essentials of veterinary hematology. Philadelphia: Lea \& Febiger, 1993. p. 417.

KANEKO, J.J.; HARVEY, J.W.; BRUSS, M.L. Clinical biochemistry of domestic animals. 5. ed. San Diego: Academic Press, 1997, cap. 5, $932 \mathrm{p}$.

LEIFER, C.E.; MATUS, R.E. Lymphoid leukemia in the dog: Acute lymphoblastic leukemia and chronic lymphocytic leukemia. Vet. Clin. North Am. Small Anim. Pract. v. 15, n. 4, p. 723-739, 1985.

LEIFER, C.E.; MATUS, R.E. Chronic lymphocytic leukemia in the dog: 22 cases (1974-1984). J. Am. Vet. Med. Ass. v. 189, n. 2, p. 214-217, 1986.
Achados bioquímicos anormais, tais como enzimas hepáticas e nitrogênio uréico sangüíneo elevados são vistos em alguns pacientes, dependendo da localização do tumor, e do grau de envolvimento dos órgãos (Thrall, 1981). No presente caso, o envolvimento de vários órgãos resultou no aumento da uréia e de várias enzimas hepáticas, demonstrando uma extensa lesão do parênquima hepático. Os autores deste trabalho acreditam que a hipoalbuminemia encontrada no presente relato pode ter sido resultado do comprometimento da síntese de proteínas pelo fígado, associada à anorexia do animal.

Ao contrário da LLA, a LLC pode assumir um curso clínico prolongado, em geral responsivo à quimioterapia em sua fase inicial (Leifer e Matus, 1986). O tratamento não é instituído até que haja sinais clínicos significativos (anemia, neutropenia, trombocitopenia), que interfiram ou ponham em risco a qualidade de vida do paciente. Animais com LLC foram acompanhados por muitos meses sem tratamento (Vail, 2000). A despeito disso, os proprietários não concordaram com o tratamento e em função do estágio avançado da doença, optaram pela eutanásia do animal.

Segundo Valli (1993), os achados macroscópicos da LLC incluem palidez discreta e gordura abdominal geralmente abundante. Segundo esse mesmo autor, à semelhança do que ocorreu no presente caso, o baço está marcadamente aumentado, macio, intensamente vermelho e seco na superfície de corte. O fígado está pelo menos moderadamente aumentado e marrom pálido com um padrão lobular. Além dessas alterações, pode haver áreas brancas focais de tumores sólidos de até $5 \mathrm{~mm}$ de diâmetro no baço, fígado e no córtex renal.

O padrão microscópico observado nesse animal é semelhante ao descrito por Valli (1993), que relata aumento maior que $90 \%$ de celularidade da medula óssea com infiltrado de células neoplásicas na medula óssea, fígado, baço e linfonodos.

MacEWEN, E.G.; YOUNG, K.M., Hematopoietic Tumors: canine lymphoma and lymphoid leukemias. In:WITHROW, S.T.; MacEWEN, E.G. (Ed). Small Animal Clinical Oncology. Philadelphia: W. B. SOUNDERS Company. 1996, p. 451-479.

MEYER, D.J.; HARVEY, J.W. Evaluation of leukocytic disorders. In: Veterinary Laboratory Medicine - Interpretation and diagnosis. Philadelphia: W. B. Sounders Company. 1998, p. 83-110.

VAIL, D. M. Tumores hematopoiéticos. In: ETTINGER, S. J.; FELDMAN, E. C. (ED). Tratado de medicina interna veterinária: doenças do cão e do gato. Rio de Janeiro: Guanabara Koogan, 2000, p. 538-555.

VALLI, V. E. O. The hematopoietic system. In: JUBB, K. V. F.; KENNEDY, P. C.; PALMER, N. Pathology of Domestic Animals. 4. ed. San Diego: Academic Press, 1993, cap. 2, p. 101-266.

THRALL, M. A. Lymphoproliferative disorders: Lymphocytic leukemia and plasma cell myeloma. Vet. Clin. North Am. Small Anim. Pract. v.11, n. 2, p. 321-347, 1981.

WALKER, D. Peripheral blood smears. In: COWELL, R.L.; TYLER, R.D.; MEINKOTH, J.H. Diagnostic Cytology and Hematology of the Dog and Cat. St. Louis: MOSBY, Inc. 1999, p. 254-283. 